\title{
Approval of antineoplastic agents in India: comparison with the US and EU regions
}

\author{
Bhaven C. Kataria ${ }^{\mathrm{a}, *}$, Dimple S. Mehta ${ }^{\mathrm{a}}$, Sunita B. Chhaiya ${ }^{\mathrm{a}}$
}

${ }^{a}$ Department of Pharmacology, C.U. Shah Medical College, Surendranagar 363001, India

Received: 19 June 2012

Revised: 29 June 2012

Accepted: 3 July 2012

*Correspondence to:

Dr. Bhaven C. Kataria,

Email: drbkataria@gmail.com

\begin{abstract}
Background: The antineoplastic drugs are prescribed for the treatment of cancer, which is an important cause of mortality in India; therefore, a drug lag in the availability of antineoplastic drugs is a direct threat to life. The present study was undertaken to assess the drug lag for new antineoplastic agents in India compared with that in the United States (US) or European Union (EU). Methods: The new antineoplastic agents approved in the United States, European Union and India between 1999 and 2011 were identified and information was gathered primarily from the websites of regulatory agencies of the three regions. We assessed absolute and relative drug lag for new antineoplastic agents approved in the three regions.

Results: Of the 70 new antineoplastic agents, 64 (91.42\%) were approved in the United States, $54(77.14 \%)$ in the European Union and $44(62.85 \%)$ in India. The US was the first to approve $59(84.28 \%)$ out of the 70 new antineoplastic agents, the EU was the first to approve $9(12.85 \%)$ and India was the first to approve $2(2.85 \%)$. The median approval lag for India (26.35 months) was higher as compared to the United States (0 month) and European Union (7.3 months).

Conclusions: This study confirms that India's drug lag in the case of new antineoplastic agents is higher as compared to the US and EU. Further detailed analyses are necessary to find the reasons and impacts of drug lag for antineoplastic agents in India.
\end{abstract}

Keywords: Oncology, anticancer drug, marketing approval, drug lag, new drug development

\section{INTRODUCTION}

As per the International Agency for Research on Cancer (IARC) estimate for India about 635000 people died from cancer in 2008. ${ }^{1}$ The recent nationally representative mortality survey in India has confirmed that more than $70 \%$ of fatal cancers occurring during the productive ages of 30-69 years. ${ }^{2}$ The antineoplastic drugs are prescribed for the treatment of cancer, which is an important cause of mortality in India; therefore, a drug lag in the availability of antineoplastic drugs is a direct threat to life. The number of cancer related deaths in India is projected to increase because of improvement in the life expectancy and population growth.

Drug development of cancer therapies has dramatically increased over the past two decades, in line with increasing understanding of the biological features of the disease and advances in technology. ${ }^{3-4}$ However, delay in approval of drugs is an important issue with increasing burden of cancer related deaths in India. Each country has specific regulatory controls that govern approval of new drugs; however, these controls often differ from country to country. Therefore, the time required for approval of a new drug may vary depending on each country's regulatory process. The United States (US) Food and Drug Administration (FDA) has done some reforms to improve the access to therapeutics for life-threatening disease by establishing accelerated approval regulations in $1992 .{ }^{5}$

There is a change in the regulatory environment after a system of product patents in India since $2005 .^{6}$ The main regulatory body for the Indian pharmaceutical industry is the Central Drugs Standard Control Organization (CDSCO). The Drug Controller General of India (DCGI) is the controlling body for the CDSCO. The office of the Drug Controller General of India is responsible for the approval of new drugs and clinical trials. The timeliness with which drug regulatory authorities approve new drugs 
for marketing affects health care professionals and patients. A long approval process delays access to new medicines that may improve patients' health status.

The drug lag for antineoplastic drugs has not been studied extensively in India, and the factors associated with this problem and impacts of drug lag remain unknown. Therefore, identifying the actual status of the antineoplastic drug lag in India would provide important information that could be used in efforts to resolve this issue. Drug lag in India may be the result of three separate types of delay or a combination of these: delay in the start of development, delay in the progress of development and delay in review by regulatory authority.

The purpose of this study was to assess the drug lag for new antineoplastic agents approved in India, in comparison with the approval of new antineoplastic agents in developed regions like the US and European Union (EU).

\section{METHODS}

\section{Data sources}

New antineoplastic agents approved in the US, EU, or India between 1999 and 2011 were identified by their International Non-proprietary Names (INN), and information was gathered primarily from the following sources:

1. The US: The Center for Drug Evaluation and Research (CDER) New Molecular Entity (NME) and New Biological Approvals, US Food and Drug Administration (FDA),

2. The EU: The European Public Assessment Report (EPAR), Committee for Medicinal Products for Human Use (CHMP), European Medicines Agency (EMA), ${ }^{8}$

3. India: The Central Drugs Standard Control Organization (CDSCO), List of drug approved for marketing in India. ${ }^{9}$

The list of approved drugs was available from 1999 through $31^{\text {st }}$ December 2011 at the time of analysis of the data. Information about name of approved drug, indication and date of issue of marketing approval was retrieved from the above sources.

New antineoplastic agents were defined as drugs having an active ingredient that has never before been marketed in the US, EU or India in any form. The following drugs were excluded: (a) vaccines, (b) combination drugs that do not include any new drugs.

\section{Analyses of drug lag}

In this study, we assessed and described the drug lag in the three regions in terms of 'absolute drug lag' and 'relative drug lag'. In assessing absolute drug lag, we used as variables the number and the percentage of approved new antineoplastic agents in each region out of a total of new antineoplastic agents approved either in the three regions in the study period. In assessing relative drug lag, two variables were used; one variable was the number and percentage of first approvals in the regions out of a total of new antineoplastic agents approved either in the three regions in the study period, and the other variable was the approval lag against the first approval granted to each antineoplastic agent in the three regions. For example, if the US was the first to approve an antineoplastic agent in January 2006 and if India approved the same antineoplastic agent in October 2006, the approval lag for the US is 0 , and the approval lag for India is 9 months.

The approval lag was obtained for all new antineoplastic agents approved in each region, and the median approval lag was calculated for each region. The new antineoplastic agents for which approval dates were unknown were excluded from the calculation of median approval lag.

Additionally, for the FDA approved drugs, the following information was collected: drug type (molecular-targeted agents/non-molecular-targeted agents), review type (standard/priority) and orphan drug status (yes/no). The molecularly targeted drugs were defined according to the National Cancer Institute fact sheet 'Targeted Cancer Therapies'. 10

\section{RESULTS}

\section{Analyses of new antineoplastic agents approved in the US, EU and India}

We identified 70 new antineoplastic agents approved either in the US, the EU, or India between 1999 and 2011. Of these 70 new antineoplastic agents, 30 were mutually approved in the three regions. The US and the EU approved 26 antineoplastic agents that were not approved in India. The EU and India approved 6 antineoplastic agents that were not approved in the US. The US and India approved 16 antineoplastic agents that were not approved in the EU. Total 40 new antineoplastic agents were approved in India during the period of 1999 to 2011 , with an average of 3.07 new antineoplastic agents approved per year. For the same period a total of 51 new antineoplastic agents were approved in the US, with an average of 3.92 antineoplastic agents approved per year and in the EU a total of 44 new antineoplastic agents were approved, with an average of 3.38 antineoplastic agents approved per year. The year wise distribution of new antineoplastic agents approved in the US, EU and India is shown in Figure 1.

\section{Analyses of drug lag}

The absolute drug lags for the US, the EU and India are shown in Table 1 . Of the 70 new antineoplastic agents, 64 $(91.42 \%)$ were approved in the US, $54(77.14 \%)$ in the EU and $44(62.85 \%)$ in India. The relative drug lags for the US, the EU and India are summarized in Table 1. The US was the first to approve $59(84.28 \%)$ out of the 70 new antineoplastic agents, the EU was the first to approve 


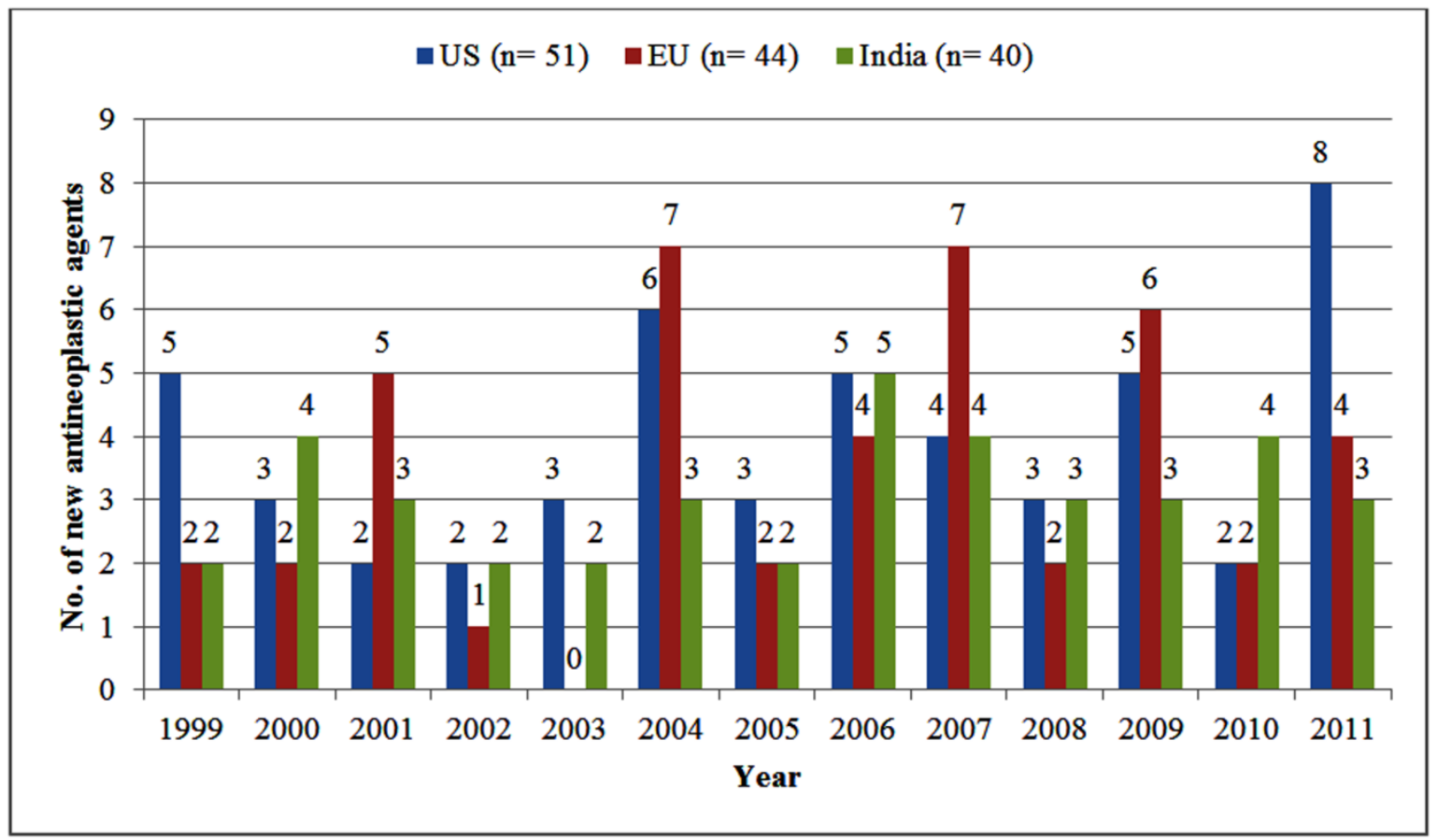

Figure 1: New antineoplastic agents approved in the US, EU and India, 1999-2011.

Table 1: Absolute and relative drug lag of new antineoplastic agents for the US, the EU and India $(n=70)$.

\begin{tabular}{llll}
\hline & US & EU & India \\
\hline Number of approvals & $64(91.42 \%)$ & $54(77.14 \%)$ & $44(62.85 \%)$ \\
Number of first approvals & $59(84.28 \%)$ & $9(12.85 \%)$ & $2(2.85 \%)$ \\
Median approval lag (months) & $0(n=61)$ & $7.3(n=50)$ & $26.35(n=40)$ \\
\hline
\end{tabular}

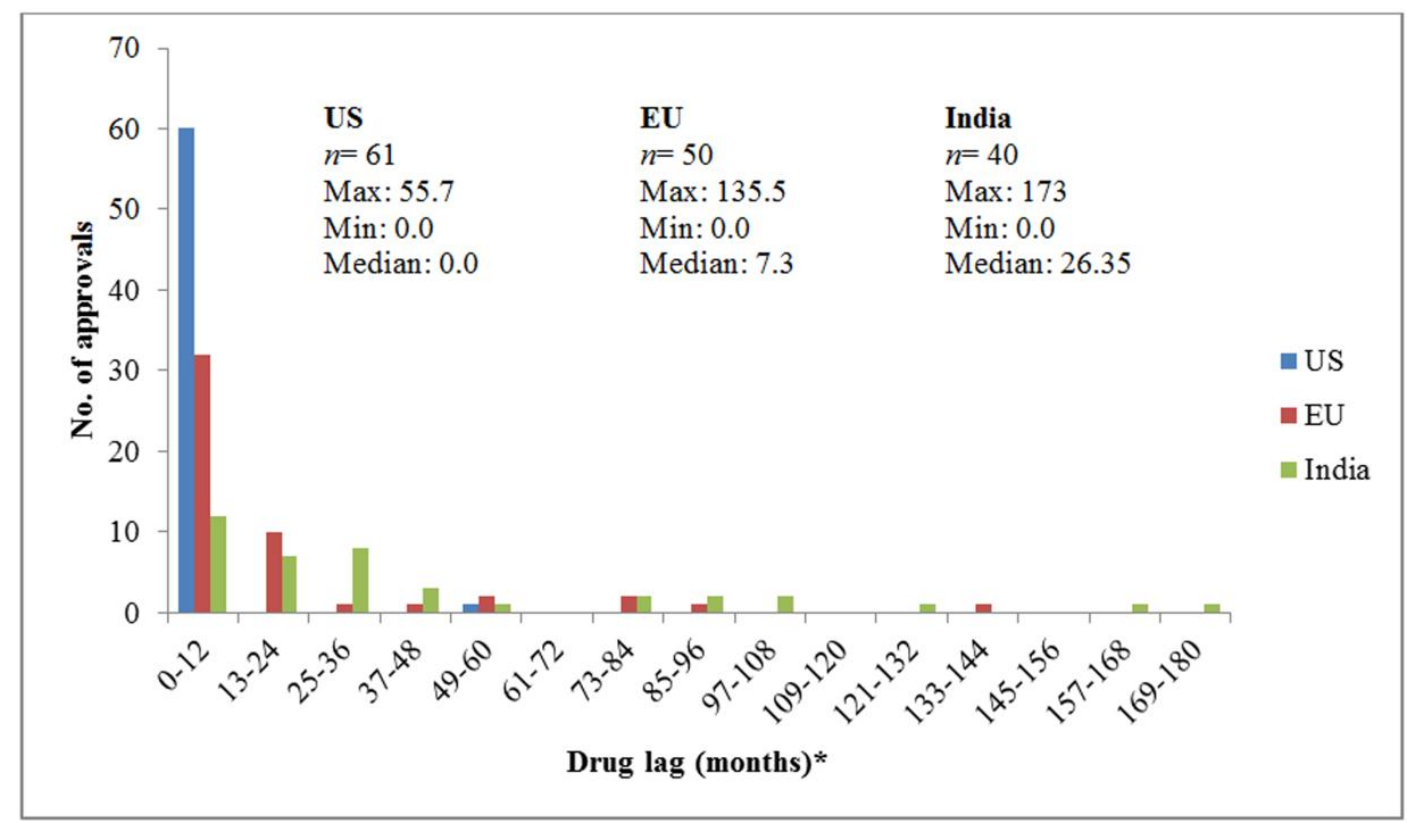

Figure 2: Distribution of drug lag for new antineoplastic agents approved in the US, EU and India. *The distribution is shown in 12-month interval. 
Kataria BC et al. Int J Basic Clin Pharmacol. 2012 Aug;1(1):13-21

Table 2: Approval dates and characteristics of new antineoplastic agents approved either in the US, EU or India from 1999 through 2011 ( $n=70$ ).

\begin{tabular}{|c|c|c|c|c|c|c|}
\hline Generic name (INN) & US approval date & EU approval date & India approval date & $\begin{array}{l}\text { Review Type }^{\S} \\
\text { (Standard/Priority) }\end{array}$ & $\operatorname{Orphan}^{\S}($ Yes/No $)$ & $\begin{array}{l}\text { Molecularly } \\
\text { targeted agent } \\
\text { (Yes/No) }\end{array}$ \\
\hline Cabazitaxel & 17-Jun-2010 & 17-Mar-2011 & 16-Nov-2011 & $\mathrm{P}^{\mathrm{a}}$ & No & No \\
\hline Abiraterone acetate & 28-Apr-2011 & 5-Sep-2011 & 16-Dec-2011 & $\mathrm{P}$ & No & No \\
\hline Crizotinib & 26-Aug-2011 & $\mathrm{NA}^{*}$ & 16-Dec-2011 & $\mathrm{P}$ & No & Yes \\
\hline Nilotinib & 29-Oct-2007 & 19-Nov-2007 & 10-Jul-2010 & $S^{\mathbb{I}}$ & Yes & Yes \\
\hline Irinotecan & 14-Jun-1996 & NA & 31-Aug-2010 & $\mathrm{P}$ & No & No \\
\hline Pazopanib & 19-Oct-2009 & 14-Jun-2010 & 16-Oct-2010 & S & No & Yes \\
\hline Temsirolimus & 30-May-2007 & 19-Nov-2007 & 11-Dec-2010 & $\mathrm{P}$ & Yes & Yes \\
\hline Trabectedin & NA & 17-Sep-2007 & 30-Mar-2009 & - & - & - \\
\hline Decitabine & 2-May-2006 & NA & 25-Apr-2009 & S & Yes & No \\
\hline Bendamustine & 20-Mar-2008 & NA & 16-May-2009 & $\mathrm{P}$ & Yes & No \\
\hline Doxifluridine & NA & NA & 31-Jan-2008 & - & - & - \\
\hline Temoporfin & NA & 24-Oct-2001 & 8-Jul-2008 & - & - & - \\
\hline Ixabepilone & 16-Oct-2007 & NA & 13-Sep-2008 & $\mathrm{P}$ & No & No \\
\hline Sunitinib & 26-Jan-2006 & 19-Jul-2006 & 10-Apr-2007 & $\mathrm{P}$ & No & Yes \\
\hline Lenalidomide & 27-Dec-2005 & 14-Jun-2007 & 16-May-2007 & $\mathrm{P}$ & Yes & No \\
\hline Lapatinib & 13-Mar-2007 & 10-Jun-2008 & 24-Jul-2007 & $\mathrm{P}$ & No & Yes \\
\hline Sorafenib & 20-Dec-2005 & 19-Jul-2006 & 31-Jul-2007 & $\mathrm{P}$ & Yes & Yes \\
\hline Cetuximab & 12-Feb-2004 & 29-Jun-2004 & 17-Aug-2006 & $\mathrm{P}$ & No & Yes \\
\hline Pemetrexed & 4-Feb-2004 & 20-Sep-2004 & 21-Aug-2006 & $\mathrm{P}$ & Yes & No \\
\hline Paclitaxel & 29-Dec-1992 & 19-Jul-1999 & 23-Aug-2006 & $\mathrm{P}$ & Yes & No \\
\hline
\end{tabular}


Kataria BC et al. Int J Basic Clin Pharmacol. 2012 Aug;1(1):13-21

\begin{tabular}{|c|c|c|c|c|c|c|}
\hline Dasatinib & 28-Jun-2006 & 20-Nov-2006 & 30-Aug-2006 & $\mathrm{P}$ & Yes & Yes \\
\hline Fulvestrant & 25-Apr-2002 & 10-Mar-2004 & 30-Aug-2006 & $\mathrm{S}$ & No & Yes \\
\hline Bortezomib & 13-Мay-2003 & 26-Apr-2004 & 18-May-2005 & $\mathrm{P}$ & Yes & Yes \\
\hline Erlotinib & 18-Nov-2004 & 19-Sep-2005 & 13-Jul-2005 & $\mathrm{P}$ & No & Yes \\
\hline Gefitinib & 5-May-2003 & 24-Jun-2009 & 17-Feb-2004 & $\mathrm{P}$ & No & Yes \\
\hline Everolimus & 30-Mar-2009 & 3-Aug-2009 & 30-Aug-2004 & $\mathrm{P}$ & No & Yes \\
\hline Gemcitabine & 15-May-1996 & 22-Jun-1996 & 1-Sep-2004 & $\mathrm{P}$ & No & No \\
\hline Anastrozole & 27-Dec-1995 & 11-Aug-1995 & 10-Feb-2003 & $\mathrm{S}$ & No & Yes \\
\hline Cladribine & 26-Feb-1993 & 14-Apr-2004 & 9-Sep-2003 & $\mathrm{P}$ & Yes & No \\
\hline Bicalutamide & 4-Oct-1995 & 5-Apr-1995 & 7-Mar-2002 & $\mathrm{S}$ & No & No \\
\hline Gemtuzumab & 17-May-2000 & NA & 12-Sep-2002 & $\mathrm{P}$ & Yes & Yes \\
\hline Vinorelbine & 23-Dec-1994 & $\mathrm{A}^{* *}$ & 17-Jan-2001 & $\mathrm{P}$ & No & No \\
\hline Exemestane & 21-Oct-1999 & 16-Dec-1998 & 18-Oct-2001 & $\mathrm{S}$ & Yes & Yes \\
\hline Imatinib & 10-May-2001 & 7-Nov-2001 & 9-Dec-2001 & $\mathrm{P}$ & Yes & Yes \\
\hline Temozolomide & 11-Aug-1999 & 26-Jan-1999 & 17-Jan-2000 & $\mathrm{P}$ & Yes & No \\
\hline Rituximab & 26-Nov-1997 & 2-Jun-1998 & 10-Jul-2000 & $\mathrm{S}$ & No & Yes \\
\hline Trastuzumab & 25-Sep-1998 & 28-Aug-2000 & 10-Jul-2000 & $\mathrm{S}$ & No & Yes \\
\hline Capecitabine & 30-Apr-1998 & 2-Feb-2001 & $12-$-Oct-2000 & $\mathrm{P}$ & No & No \\
\hline Topotecan & 28-May-1996 & 12-Nov-1996 & 15-Jun-1999 & $\mathrm{P}$ & No & No \\
\hline Fludarabine & 18-Apr-1991 & 11-Aug-1994 & 26-Jun-1999 & $\mathrm{P}$ & Yes & No \\
\hline Vandetanib & 4-Jun-2011 & NA & NA & $\mathrm{P}$ & No & Yes \\
\hline Vemurafenib & 17-Aug-2011 & NA & NA & $\mathrm{P}$ & No & Yes \\
\hline
\end{tabular}


Kataria BC et al. Int J Basic Clin Pharmacol. 2012 Aug;1(1):13-21

\begin{tabular}{|c|c|c|c|c|c|c|}
\hline Ipilimumab & 25-Mar-2011 & 13-Jul-2011 & NA & $\mathrm{P}$ & Yes & Yes \\
\hline Brentuximab vedotin & 19-Aug-2011 & NA & NA & $\mathrm{P}$ & Yes & Yes \\
\hline Ruxolitinib & 16-Nov-2011 & NA & NA & $\mathrm{P}$ & Yes & Yes \\
\hline $\begin{array}{l}\text { Asparaginase Erwinia } \\
\text { Chrysanthem }\end{array}$ & 18-Nov-2011 & NA & NA & $\mathrm{P}$ & Yes & No \\
\hline Eribulin & 15-Nov-2010 & 17-Mar-2011 & NA & $\mathrm{P}$ & No & No \\
\hline Pralatrexate & 24-Sep-2009 & NA & NA & $\mathrm{P}$ & Yes & Yes \\
\hline Romidepsin & 5-Nov-2009 & NA & NA & $\mathrm{S}$ & Yes & Yes \\
\hline Ofatumumab & 26-Oct-2009 & 19-Apr-2010 & NA & $\mathrm{P}$ & Yes & Yes \\
\hline Plerixafor & 15-Dec-2008 & 31-Jul-2009 & NA & $\mathrm{P}$ & Yes & No \\
\hline Degarelix & 24-Dec-2008 & 17-Feb-2009 & NA & $\mathrm{S}$ & No & No \\
\hline Vorinostat & 6-Oct-2006 & NA & NA & $\mathrm{P}$ & Yes & Yes \\
\hline Panitumumab & 27-Sep-2006 & 3-Dec-2007 & NA & $\mathrm{P}$ & No & Yes \\
\hline Nelarabine & 28-Oct-2005 & 22-Aug-2007 & NA & $\mathrm{P}$ & Yes & No \\
\hline Azacitidine & 19-May-2004 & 17-Dec-2008 & NA & $\mathrm{P}$ & Yes & No \\
\hline Clofarabine & 28-Dec-2004 & 29-May-2006 & NA & $\mathrm{P}$ & Yes & No \\
\hline Bevacizumab & 26-Feb-2004 & 12-Jan-2005 & NA & $\mathrm{P}$ & No & Yes \\
\hline Abarelix & 25-Nov-2003 & NA & NA & $\mathrm{P}$ & No & No \\
\hline Oxaliplatin & 9-Aug-2002 & A & A & $\mathrm{P}$ & No & No \\
\hline Triptorelin & 15-Jun-2000 & A & A & $\mathrm{S}$ & No & No \\
\hline Arsenic trioxide & 25-Sep-2000 & 5-Mar-2002 & A & $\mathrm{P}$ & Yes & No \\
\hline Alitretinoin & 2-Feb-1999 & $11-$ Oct-2000 & NA & $\mathrm{P}$ & Yes & Yes \\
\hline Epirubicin & 15-Sep-1999 & A & A & $\mathrm{P}$ & Yes & No \\
\hline
\end{tabular}


Kataria BC et al. Int J Basic Clin Pharmacol. 2012 Aug;1(1):13-21

\begin{tabular}{|c|c|c|c|c|c|c|}
\hline Bexarotene & 29-Dec-1999 & 29-Mar-2001 & NA & $\mathrm{P}$ & Yes & Yes \\
\hline 5-Aminolevulinic acid & NA & 7-Sep-2007 & NA & - & - & - \\
\hline Vinflunine & NA & 21-Sep-2009 & NA & - & - & - \\
\hline Alemtuzumab & 7-May-2001 & 6-Jul-2001 & NA & $S$ & No & Yes \\
\hline Catumaxomab & NA & 20-Apr-2009 & NA & - & - & - \\
\hline Anagrelide & 14-Mar-1997 & 16-Nov-2004 & NA & $\mathrm{P}$ & Yes & No \\
\hline
\end{tabular}

* NA: Not approved, **A: Available, but approval date is not known, ${ }^{\S}$ Characteristics for the FDA approved drugs

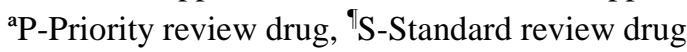


$9(12.85 \%)$ and India was the first to approve $2(2.85 \%)$. The median approval lag for India (26.35 months) was higher as compared to the United States (0 month) and European Union (7.3 months). The distribution of approval lags for each region are shown in Figure 2. Although the approval lag was less than one year for most of the antineoplastic agents for the US and the EU, India had a different distribution profile. The 12 new antineoplastic agents were approved in India within first 12 months of drug lag interval and showed a wide distribution up to nearly 173 months (Figure 2).

The relative drug lag was assessed for the 30 'mutually approved new antineoplastic agents'. The US was the first to approve $25(83.33 \%)$ out of the 30 mutually approved new antineoplastic agents, the EU was the first to approve $4(13.33 \%)$ and India was the first to approve $1(3.33 \%)$. Again the median approval lag for India (27.15 months) was higher as compared to the United States (0 month) and European Union (7.3 months) for the mutually approved new antineoplastic agents.

The approval dates and characteristics of new antineoplastic agents approved either in the US, EU or India is shown in Table 2. Of the 64 new antineoplastic agents that were approved by the FDA, 51 (79.68\%) were priority review drugs; $13(20.31 \%)$ were standard review drugs; $33(51.56 \%)$ received orphan drug status; 34 $(53.12 \%)$ were molecularly targeted drugs and 30 (46.88\%) were non-molecularly targeted drugs.

\section{DISCUSSION}

The percentage of approval of new antineoplastic agents was more than $90 \%$ for the US and almost $80 \%$ for the EU, $44(62.85 \%)$ of the 70 new antineoplastic agents were approved in India. Thus, India is behind in comparison to the US and EU regions in terms of absolute drug lag. The US was the first to approve the majority of the new antineoplastic agents, and the EU was slightly delayed (Median approval lag: 7.3 months). But, the considerable delay was observed for India in approval of new antineoplastic agents. The median approval lag for India (26.35 months) was more than 2 years longer than that for the US (0 month) and 1.5 years longer than that for the EU (7.3 months). While our study showed that the US was first to approve majority of the new antineoplastic agents, the relative drug lag for EU was not so high. Therefore, it can be assumed that the drug lag in the EU was simply a slight delay in approval, which may be attributed to a delay in the start of development and may be a slightly longer review period.

The US FDA has given New Molecular Entity (NME) status for thalidomide in 1998. However, we excluded thalidomide from our analysis as its old drug approved for multiple myeloma by the US FDA and EMA. ${ }^{7-8}$ Thalidomide was withdrawn due to its association with foetal malformation. In 2002, thalidomide was made available again in India. Marketing authorisation for gemtuzumab and pralatrexate was refused by EMA. ${ }^{8}$ Both these drugs are approved by the US FDA. In 2009, Merck Sharp \& Dohme Ltd has notified EMA to withdraw its application for a centralised marketing authorisation for the medicine vorinostat. ${ }^{11}$

Due to the limitations of this study, it is not possible to make an analysis of the possible reasons behind these delays. However, delay in the start of development, delay in the progress of development and delay in review by the regulatory authority could be possible reasons behind these delays in approval of antineoplastic agents in India. Besides, delay in review by the regulatory authority, this study suggests that the drug lag may be associated with delays in the initiation of drug development in India. One possible reason for the delays may be that pharmaceutical companies believe that simultaneously conducting registration trials in India and in the US or EU is a risk. As per World Trade Organisation (WTO), from the year 2005 , India granted product patent recognition to all new chemical entities (NCEs). ${ }^{6}$ Though, many foreign multinational corporations (MNCs) are not taking risk to launch their patented new drugs in India simultaneously with the developed markets. The questions on India's intellectual property (IP) regime are raised after Bayer has lost a landmark drug ruling in India, forcing it to grant a compulsory licence for its cancer treatment Sorafenib (Nexavar) to the Indian company, Natco Pharma. ${ }^{12}$ To resolve delays in the initiation of drug development in India, pharmaceutical companies should make an effort to enrol Indian patients in international registration trials. For majority of new drugs, drug development is being performed in the US and the EU concurrently, and the integrated data package may be used for new drug applications (NDAs) in the US and the EU. Thus, it was not surprising that there was a little time gap in new drug approvals between the US and the EU.

Compared with the US and the EU, a striking drug lag was observed for approval of new antineoplastic agents in India. This may be because the US or Europe based companies were not interested to introduce the new antineoplastic agents through their subsidiaries in India due to relaxed patent law in India before 2005. The majority of large multinational pharmaceutical companies have presence in India and they may try to introduce their new products in India, simultaneously with other markets. Now, because of product patent in India, the Indian pharmaceutical companies can't introduce patented drugs developed by the foreign multinational corporations (MNCs). With the introduction of product patents, Indian companies will have to shift the area of focus from process development to developing new drug products.

Drug development is becoming increasingly globalised and to conduct the clinical trials in India is relatively economical as compared to other developed markets. However, there is a need to improve the regulatory processes in India to enhance the clinical trial and new drug approvals. The Indian regulatory authority has to 
initiate some measures to reduce this delay in approval. The Japanese government has initiated various direct and indirect measures to reduce drug lag in Japan. ${ }^{13}$ There is an urgent need to increase the human resources and improvement in the regulatory processes in India.

In conclusion, our analysis confirms that India's drug lag in the case of new antineoplastic agents is quite substantial. The drug lag in India may be attributed to a delay in the start of development, a delay in the progress of development, late submission of NDA and a delay in review by the regulatory authority. Further detailed analyses are necessary to find the background factors responsible for delay in approval in India and assess the impacts of drug lag for antineoplastic agents. To reduce this delay, combined efforts are required by the Indian regulatory agency and pharmaceutical companies.

\section{REFERENCES}

1. Ferlay J, Shin HR, Bray F, Forman D, Mathers C, Parkin DM. Estimates of worldwide burden of cancer in 2008: GLOBOCAN 2008. Int J Cancer 2010; 127: 2893-917.

2. Dikshit R, Gupta PC, Ramasundarahettige C, Gajalakshmi V, Aleksandrowicz L, Badwe R et al. Cancer mortality in India: a nationally representative survey. Lancet 2012; 379:1807-16.

3. Reichert JB, Wenger JB. Development trends for new cancer therapeutics and vaccines. Drug Discov Today 2008; 13:30-7.

4. Chin L, Andersen JN, Futreal PA. Cancer genomics: from discovery science to personalized medicine. Nat Med 2011; 17:297-303.

5. Clinton W, Gore A: Reinventing the regulation of cancer drugs: National performance review, 1996. Available http://www.fda.gov/ohrms/dockets/ac/05/briefing/20 05-4191B1_01_03-Reinvent-Cancer-Drugs.pdf. Accessed 9 April 2012.

6. Report of the working group on drugs and pharmaceuticals for the eleventh five-year plan (2007-2012), Planning commission of India. Available at http://planningcommission.nic.in/aboutus/committee /wrkgrp11/wg11_pharma.pdf. Accessed 3 April 2012.

7. U.S. Food and Drug Administration. NME drug and new biologic approvals. Available at http://www.fda.gov/Drugs/DevelopmentApprovalPr ocess/HowDrugsareDevelopedandApproved/Drugan dBiologicApprovalReports/ucm121136.htm.

Accessed 19 March 2012.

8. European Medicines Agency. The European Public Assessment Report. Available at http://www.ema.europa.eu/ema/index.jsp?curl=page s/medicines/landing/epar_search.jsp\&jsenabled=true . Accessed 19 March 2012.

9. The Central Drugs Standard Control Organization (CDSCO). List of drug approved for marketing in
India. Available at http://cdsco.nic.in/listofdrugapprovedmain.html. Accessed 19 March 2012.

10. National Cancer Institute. Fact sheet: targeted cancer therapies, 2012. Available at http://www.cancer.gov/cancertopics/factsheet/Thera py/targeted\#q1. Accessed 9 April 2012.

11. European Medicines Agency. Merck Sharp \& Dohme Ltd withdraws its marketing authorisation application for Vorinostat MSD. February 17, 2009. Available at http://www.ema.europa.eu/ema/index.jsp?curl=page s/news_and_events/news/2009/11/news_detail_0001 15.sjsp\&jsenabled=true. Accessed 9 April 2012.

12. U.S. questions India's IP regime after Nexavar move. By Tracy Staton, March 27, 2012. Available at http://www.fiercepharma.com/story/us-questionsindias-ip-regime-after-nexavar-move/2012-03-27. Accessed 9 April 2012.

13. Yonemori K. Hirakawa A et al. The notorious "drug lag" for oncology drugs in Japan. Invest New Drugs 2011; 29:706-12. 